\title{
Improvement of design parameters of planetary multipliers and reducers, using specialized author's software for joined gears drives
}

\author{
Peter Nenov ${ }^{1 *}$, Bojidar Kaloyanov ${ }^{2}$, Plamen Danev ${ }^{3}$ \\ ${ }^{1}$ Pr. Eng.PhD, ME-Department, UR - Ruse, ${ }^{2}$ ScC Eng.M.S, SRSector, UR - Ruse, \\ ${ }^{3}$ Eng, Chif.designer, MB Factory - Module, Biala/Ruse, Bulgaria
}

\begin{abstract}
The present work discus two indicative cases from the practice, in which the final results significantly exceed those of the "base" multiplier and the ,initial“ reducer. The constructions are promising for the development of electricity generation from tides, respectively - for the electric hoist industry. The first reconstruction includes detailed analysis and substantial changes of the entire product, focusing on important changes to its structural and technological parameters that will make it feasible. At the same time, in the both projects, using author's specialized software, multi-variance design and parallel analysis of the results good solution very near to their optimal values was found. The additional goal of the authors is to share how this approach and tools, combined with successful machine-building design systems, can contribute to raising the level of all power gears drives.
\end{abstract}

\section{Introduction}

Recently, gear drives designers have benefited from a rich arsenal of high quality professional computers programs. With their help, the design of gearing and other gear mechanisms is greatly facilitated, and reduces the risk of hard-to-repair errors. This has expanded the scope of service designers. But sometimes there is obviously a certain underestimation from the work conditions and the technologies for producing this kind of products. And also a tendency to simplify the resolving process through unjustified recommendations, because of the distance from the specificities of the meshes.

In more complex cases there are connected gears in which the gears participate simultaneously in more than one gearing - real or conditional, taking into account technological, economic, etc. reasons [1], [2], [8]. This makes the design process more difficult and more responsible. One of the many examples of this is the requirement for equal center distances of gear drives with different gear ratios, such as in the popular families of speed reducers [3]. In other cases, there is an unjustified emphasis on rounded gear ratios.
Successful solutions can also be missed in families of gears with internal gearings, without looking for the equal number of teeth of central tooting, allowing for close sizes of the expensive blanks. And it is a coincidence in planetary multistage gears to find the same values (not equal to zero!), of addendum modification coefficients of central gears with internal teeth which ensures full equality of all geometric parameters of the tooting. In certain cases this could allow the replacement of two big central neighboring gears with a single machine element. Very often, the design of multistage planetary gears may also be hampered by requiring neighboring stairs to have a different number of satelites...

Known software can hardly provide high-quality solutions to similar issues. And it is normally good solutions to be sought with the combined use of software, including author's systems, to create blocking contours, such as ,center distances - addendum modification coefficients". By the way, in real projects the optimal solutions are difficult even for definition. Therefore, it is good when the final choice is at least close to them, which is also a matter of compromises [4].

Corresponding author: pnenov@gmail.com 
a)

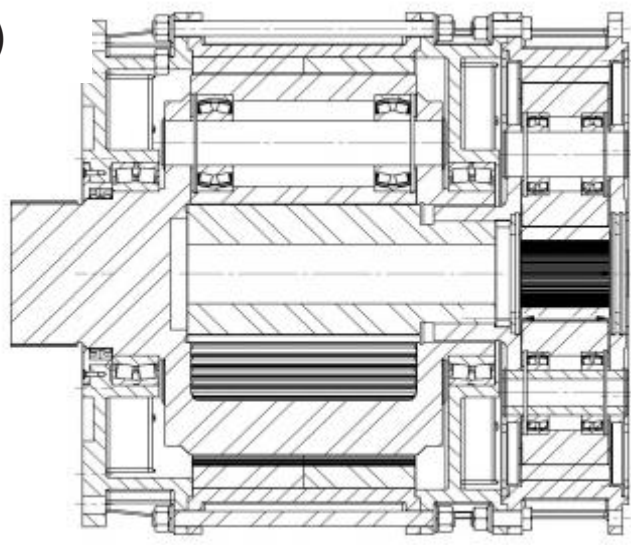

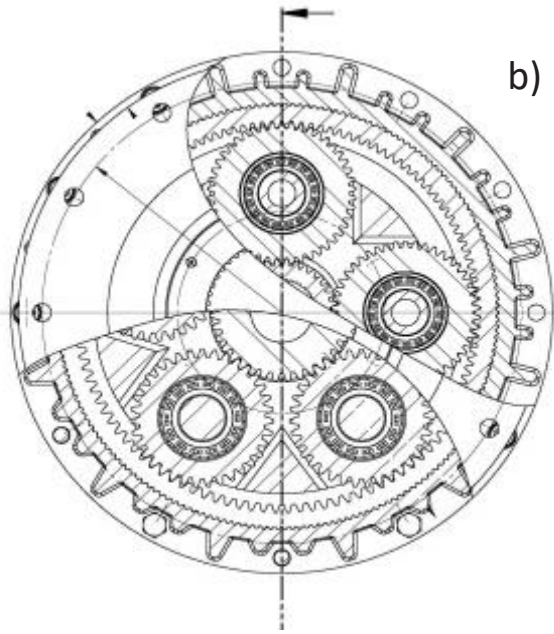

Fig.1. A main section of the "base" planetary multiplier [5B]

The current research work and recomendations are based on real examples from the practice, when highparameters of the desing products are looking for. The purpose of the first development is to create an improved version of two stage planetary gear multiplier for a hydromechanical power generator, operating in a sea environment.

\section{Multiplier for hydro generator}

The demand to redesigned gearbox needs it's new version to cam built into the space, definite at the beginning of the complex innovative project.This requires the modification to be not to far from the „base“ design and the new solution to respode to the higher load capacity requirements, without departing from the direction already set. At the same time, obvious serious violations with constructive nature, as well as neglecting technological requirements, make the task difficult to implement (Fig.1).

\subsection{Analysis of the "base" multiplier}

The analysis of the geometric and kinematic parameters of the multiplier is carried out by computer research, according to the project documentation [5B] (excluding the computational part).

Design revision is based on specialized author's software and includes assessment of gear geometry, including creation of blocking contours for external, internal and connected gearing. It is also important to meet the compatibility requirements. Generated Geometric Blocking Contours, , $\mathrm{a}_{\mathrm{w}}-\mathrm{x}_{\mathrm{i}}{ }^{\text {“ }}$ type (GBC) for external (E:a-g), internal (I:g-b) and connected (C-GDB) gearing showed that their geometry is acceptable, in principle. The specific requirements for planetary gears type 2K-H - co-axial position, symmetry, and „neighborhood“ are also set [6]. And probably for simplifying the calculations, all gears are with ziro values of their addendum modification coefficients. With strength calcul of the gear drives, their load capacity by the two main criteria - bending strength and contact strength are also avaiable. The results from the step-bystep calcul are shown in the Table 1A, line 1. Formally, they are also good, but at Kun=1,0.

Table 1. Load caring capacity of the first (slow-moving) stage of the ,base“ multiplier

A.Load capacity of the gearing, computing with author's system \#GEAR; Number of satellites - 1 (conditional)

\begin{tabular}{|c|c|c|c|c|c|c|c|}
\hline \multirow[t]{2}{*}{$\mathrm{Ng}$} & \multirow[t]{2}{*}{$\mathrm{m}$} & \multirow{5}{*}{$\begin{array}{c}\text { bw }=250 \mathrm{~mm} \\
\text { Tooting ring } \\
42 \mathrm{CrMo4} / \\
\text { HRC45;Kun=1 } \\
\text { Ac.g.:8-8-8-B } \\
\text { Nsat }=1 \text { (cond) }\end{array}$} & \multicolumn{2}{|c|}{$\mathrm{PF}$} & \multicolumn{2}{|c|}{ PH } & \multirow{2}{*}{$\begin{array}{c}\mathrm{P}, \\
\mathrm{kW}\end{array}$} \\
\hline & & & a-g & $g-b$ & $a-g$ & g-b & \\
\hline 1 & 5 & & 260 & 205 & 275 & 215 & 205 \\
\hline 2 & 6 & & 315 & 250 & 610 & 225 & 225 \\
\hline 3 & 7 & & 345 & 280 & 575 & 215 & 215 \\
\hline
\end{tabular}

Gear drives: Module $\mathbf{m}=\mathbf{5} \mathbf{~ m m}, \quad Z a, g, b=35-35-105$;

$\mathrm{m}=6 \mathrm{~mm} \quad Z a, g, b=30-30-90 ; \quad m=7 \mathrm{~mm} \quad Z a, g, b=25-25-75$,

without addendum modification coefficients : ( $x a, g, b=0)$

B. Load capacity of the planetary stage, computing with system PLANET; Number of satellites - 5 (five); Kun=1

\begin{tabular}{|c|c|c|c|c|c|c|c|}
\hline \multirow[t]{2}{*}{$\mathrm{Ng}$} & \multirow[t]{2}{*}{$\mathrm{m}$} & \multirow{3}{*}{$\begin{array}{c}\text { bw }=160 \mathrm{~mm} \\
\text { Tooting ring } \\
42 \mathrm{CrMo} 4 /\end{array}$} & \multicolumn{2}{|c|}{$\mathrm{PF}$} & \multicolumn{2}{|c|}{$\mathrm{PH}$} & \multirow{2}{*}{$\begin{array}{c}\mathrm{P}, \\
\mathrm{kW}\end{array}$} \\
\hline & & & a-g & g-b & a-g & $g-b$ & \\
\hline 1 & 5 & & 900 & 705 & 845 & 835 & 705 \\
\hline 2 & 6 & HB350 & 1085 & 980 & 885 & 880 & 880 \\
\hline 3 & 7 & $\begin{array}{l}\text { Ac.g.: } 8-8-8-B \\
\text { Nsat }=5 \text { (five) }\end{array}$ & 840 & 905 & 725 & 795 & 725 \\
\hline
\end{tabular}

C.Comparison of a load capacity of the slow-moving stage at a different Accuracy grades and the Coefficient of Unevenness Kun; Number of the satellites - 5 (five) (\#PLANET - author's software)

\begin{tabular}{|c|c|c|c|c|c|}
\hline $\mathrm{Ng}$ & $\mathrm{m}$ & \multirow{5}{*}{$\begin{array}{c}\text { bw }=160 \mathrm{~mm} \\
\text { Tooting wrist } \\
\text { 42CrMo4/ } \\
\text { HB350 } \\
\text { Nsat }=5 \text { (five) }\end{array}$} & \multirow{3}{*}{$\begin{array}{c}\text { Accuracy } \\
\text { Grades }\end{array}$} & $\begin{array}{l}\text { Натоварване } \\
\text { на сателитите }\end{array}$ & $\begin{array}{l}\mathrm{P}, \\
\mathrm{kW}\end{array}$ \\
\hline 1 & 5 & & & Kun $=1,2$ & 590 \\
\hline 2 & 6 & & & Kun $=1,2$ & 735 \\
\hline 3 & 6 & & $8-8-8-B$ & Kun=1,5 & 585 \\
\hline 4 & 6 & & 7-7-7-B & Kun $=1,2$ & 765 \\
\hline
\end{tabular}

Obviously from the beginning a great width of the gearing was reduced from $292 \mathrm{~mm} \mathrm{bw}=250 \mathrm{~mm}$. 


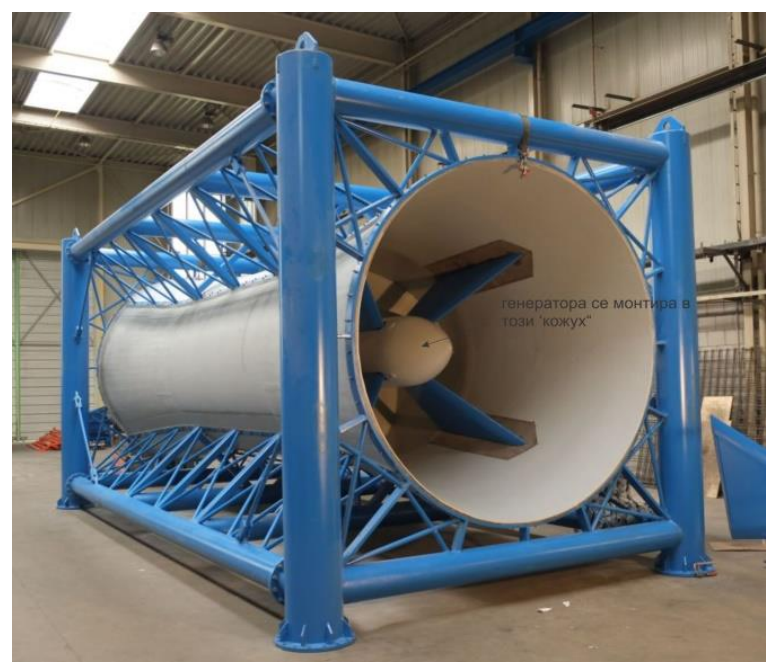

Fig.2. Hydro mechanical power generator [5A]

I'he design problems of the construction, accepted as a „base“ are many. Among the first is the width of the gears, which is too big and violate the accepted norms and practices (Fig.1a). Therefore the narrowing of the gears width ought to go on.

The load capacity of the gears is determined by the program \#GEAR - conditionally, for outboard gears with external (E), resp. internal (I) engagement. In this way, the input information provides for the necessary uniformity of the gear rotation speeds in the independent gears and the gears in the planetary stage, and the coefficient for distribution of the load between the satellites is with the coefficient of unevenness Kun=1.

The introduced splitting of the toothed ring into two parts, and introduced spline connection with the housing (Fig.1b) does not solve the problem, but is a serious obstacle to achieving the prescribed high accuracy degrees of gearing (7-B). Due to limitations in the radial dimensions, a heavy problem with the material and the heat treatment of the central toothed wrist (ring) and its high hardness - HRC60 appear.
In Table 1, Part A, study results are given for $\mathrm{bw}=250$ $\mathrm{mm}$, at Kun=1 (conditionally). Formally the allowable power is in the face. The selected perspective options have also been verified with the program system for verifying and designing Planetary gear drives (\#PLANET). Specified capacity is allowed, with equal loading of all satellites (which is not possible even theoretically!). Many solutions of lesser width, with less hardness of tooth wreaths, with different modules and coefficients Kun $>1$ are analyzed. After many variations, there has been found acceptable narrowing of the gearing - Part B, line 2 - a $160 \mathrm{~mm}$ wide version with 5 satellites made of the same $42 \mathrm{CrMo} 4$ steel, and a lower hardness (HB350). Also included are gears with larger modules (and a smaller number of teeth allowing entry into the same housing!). The final solution is for a $160 \mathrm{~mm}$ wide tooting and HB350 hardness. Data in the part C of Table 1 allow comparing the results for gearings in different modules, degrees of accuracy and irregularity. All the solutions showed fit into the set dimensions of the multiplier and the body of hydro-tub (Fig. 2). From those preliminary design the most promising are the gears with module $\mathrm{m}=6 \mathrm{~mm}$ and width $\mathrm{bw}=160 \mathrm{~mm}$.

\subsection{Modifying the planetary gearing of the first stage of multiplier}

A leading idea is the full use of any possible measures to reduce the unevenness in satellite loading. In the chosen schematic design, this is difficult to achieve because it has no compensating elastic elements. The danger of major technological inaccuracies makes it imperative to remove the spline connection with the cylindrical housing. In the new development (Fig. 3) the planet carrier has been reduced and improved in strength, functionality and technology. This allows for greater accuracy in its execution. his allows for more accurate execution. The power of possible improvements can be felt by generating additional gears, comparative calculations, selecting appropriate technology bases, reducing unevenness under Kun=1.5 .
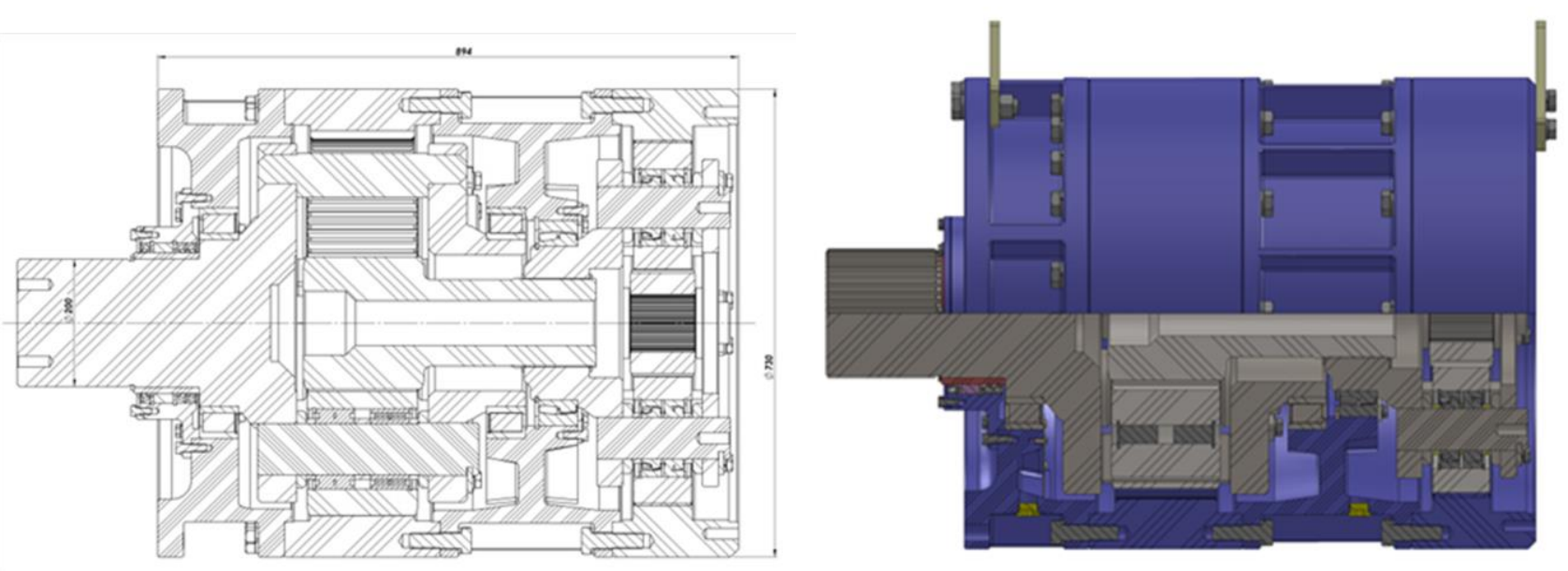

Fig.3. Sections of the modifying version of the planetary multiplier [5B] 
The idea for removing the spline joint ensures space in the radial direction and makes possible the increasing the diameters of the gears and the planet carrier.

Table 2. New possibilities of the slow-rotating stage, after removing the spline joint with the housing

\begin{tabular}{|c|c|c|c|c|c|}
\hline \multicolumn{6}{|c|}{ Slow-rotating stage-main parameters of the gearing: } \\
\hline \multicolumn{6}{|c|}{$\begin{array}{l}\text { Gear drives: Numbers of tooth: } \mathrm{Za}=32 \mathrm{Zg}=33 \mathrm{Zb}=98 \text {; } \\
\text { Module } \mathbf{m}=\mathbf{6} \mathrm{mm} ; \quad \text { Numbers of the satellites } 5 \text { (five) } \\
\text { Coefficient of unevenness of satellite load - Kun=1,5 }\end{array}$} \\
\hline \multirow[t]{2}{*}{ № } & \multirow[t]{2}{*}{$\begin{array}{l}\mathrm{aw}, \\
\mathrm{mm}\end{array}$} & $\begin{array}{l}\text { Addendum modif. } \\
\text { coefficients }\end{array}$ & \multicolumn{3}{|c|}{$\begin{array}{l}\text { Allowable } \\
\text { power, } \mathrm{kW}\end{array}$} \\
\hline & & $\mathrm{xg} \quad \mathrm{xb}$ & PF & Pgen & PH \\
\hline 1 & \multirow{5}{*}{195} & 0 & 570 & 570 & 570 \\
\hline 1.1 & & $0,2 \quad-0,2 \quad-0,2$ & 650 & 530 & 530 \\
\hline 1.2 & & $-0,2 \quad 0,2 \quad 0,2$ & 615 & 525 & 525 \\
\hline 1.3 & & $\begin{array}{lll}0,4 & -0.4 & -0,4\end{array}$ & 650 & 495 & 495 \\
\hline 1.4 & & $-0,4 \quad 0,4 \quad 0,4$ & 700 & 490 & 490 \\
\hline 2 & 196 & $0,17 \quad 0 \quad 0,17$ & 570 & 570 & 635 \\
\hline 3 & 197 & $0,346 \quad 0 \quad 0,346$ & 570 & 570 & 645 \\
\hline 4 & 199 & $\begin{array}{lll}0,400 & 0 & 0,400\end{array}$ & 570 & 570 & 650 \\
\hline 5 & 199,44 & $0,800 \quad 0 \quad 0,800$ & 570 & 570 & 665 \\
\hline 6 & 200 & $0,908 \quad 0 \quad 0,908$ & 570 & 570 & 670 \\
\hline \multicolumn{6}{|c|}{$\begin{array}{l}\text { Materials, Heat-treatment : Central gear (pinion ) and } \\
\text { satellites - } 18 X \Gamma \mathrm{X} / \mathrm{HRC} 60 \text {; Toothed wrist (ring)-42CrMo4/ } \\
\text { HB350, bw }=160 \mathrm{~mm} \text {; Accuracy grades } 8-8-8-\mathrm{B}\end{array}$} \\
\hline
\end{tabular}

The exploration of the new possibilities is outlined in increase in the number of teeth of all gears: $\mathrm{Za} 32 ; \mathrm{Zg}=33$; $\mathrm{Zb}=98$. As a result, and at zero addendum modification coefficients, the allowable output power is higher - taking into account the greater unevenness (Kun=1.5). The new planetary gear with a center distance aw $=195 \mathrm{~mm}$ is also developed in four additional variants with zero summary addendum modification coefficient. Two of them have positive values of the coefficient of the central sun gear, Selected prospective variants are tested on both power criteria by the help of the program system (\#PLANET).
The part $\mathrm{C}$ compares the results for different modules, degrees of accuracy and coefficients of unevenness of the load.

and the other two - with negative. With a positive values of the coefficient of central sun gear its bending strength increases, but the bending strength of the satellite gear decreases. However, as the number of teeth of the gears of the external drives is practically equal, the load capacities of the four versions vary insignificantly. This detain the capabilities of the entire stage even at an "angular corrections" with a positive modification coefficient at which the center distance increases. The reason is that the satellites diameters (they are zero at the adopted correction scheme) are kept roughly the same because the contribution of the increase in the center distance (the arm of the forces) is neglected. With the lime 3 of Table 2, additional studies suggesting the effect on the permissible power and other factors such as the degree of accuracy, the unequal loading of the individual branches $(\mathrm{Kun} \neq 0)$, the hardness of the teeth, etc. (Table 4). Increasing the total load capacity can also be sought through changes in the distribution of the overall gear ratio between the two stages (see below).

\subsection{Second Stage of the Multiplier and Improvement of planetary gears via Connected- G.B. Contours}

Verification of the strength characteristics of the second (fast) stage of the multiplier, based on data from the "base" version - module $\mathrm{m}=4 \mathrm{~mm}$ and number of teeth 39-51-141 (Table 4). Its allowable power capacity is much higher than required, so a certain decreasing of the gear width has been made.

There is also an opportunity to increase the load capacity of the first stage at the expense of the resource but the second one. For this purpose, new versions have been generated tor distribution the total gear ratio Uo [9] .

Table 3. Computing load capacity - study of the planetary gearing version with center distance $\mathrm{a}_{\mathrm{w}}=197 \mathrm{~mm}$, obtained by replacing the spline joint of the "base" multiplier with common wrist (ring)

General Input Parameters of the slow-moved (first) stage : $\quad \mathrm{Za}=32 \mathrm{Zg}=33 \mathrm{Zb}=98 ; \quad \mathrm{m}=6 \mathrm{~mm} ; \quad$ numbers of satellites - 5; Centre distance $a_{w}=197 \mathrm{~mm}$; Width $b_{w}=160 \mathrm{~mm}$; Addendum modification coefficients : $x a=x b=0.346, \quad x g=0$

\begin{tabular}{|c|c|c|c|c|c|c|c|c|c|c|c|c|c|c|c|c|}
\hline \multirow{3}{*}{ 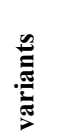 } & \multicolumn{5}{|c|}{ Input information } & \multirow{2}{*}{\multicolumn{5}{|c|}{$\begin{array}{l}\text { Allowable power/bend., kW-PF } \\
\text { Ext.gear.(E) / Int.gear.ing (I) }\end{array}$}} & \multirow{3}{*}{$\begin{array}{c}\text { P gen } \\
\mathrm{kW}\end{array}$} & \multirow{2}{*}{\multicolumn{5}{|c|}{$\begin{array}{l}\text { Allowable power/cont., kW-PH } \\
\text { Ext. gear.(E) / Int. gear.(I) }\end{array}$}} \\
\hline & \multicolumn{3}{|c|}{ Gear's materials } & \multirow{2}{*}{\multicolumn{2}{|c|}{$\begin{array}{l}\text { Accuracy } \\
\text { grades;Kun }\end{array}$}} & & & & & & & & & & & \\
\hline &, $\mathrm{a}^{6}$ & ,g“ & ,b“ & & & & & $(\mathrm{g}$ & & PF & & $\mathbf{P H}$ & & & $\mathrm{g}$ & \\
\hline 3. & \multirow{2}{*}{\multicolumn{2}{|c|}{ M1 }} & M3 & $8-8-8$ & 1,5 & 610 & 570 & 685 & 700 & 570 & 495 & 495 & 645 & 645 & 2350 & 495 \\
\hline 3.1 & & & \multirow{5}{*}{ M2 } & $8-8-8$ & 1,5 & 610 & 570 & 675 & 595 & 570 & 570 & 645 & 645 & 645 & 2340 & 730 \\
\hline 3.2 & $\mathrm{M} 1, \mathrm{~m}$ & $\mathrm{Car}$ & & $8-8-8$ & 1,5 & 615 & 695 & 830 & 700 & 615 & 615 & 650 & 650 & 650 & 2350 & 730 \\
\hline 3.3 & \multirow{3}{*}{\multicolumn{2}{|c|}{ M1 }} & & $7-7-7$ & 1,5 & 615 & 575 & 685 & 705 & 575 & 575 & 675 & 675 & 675 & 2340 & 760 \\
\hline 3.4 & & & & 8-8-8 & 1,7 & 540 & 505 & 605 & 615 & 505 & 505 & 570 & 570 & 570 & 2070 & 645 \\
\hline 3.5 & & & & $8-8-8$ & 1,0 & 915 & 855 & 1030 & 1050 & 855 & 855 & 970 & 970 & 970 & 3520 & 1095 \\
\hline
\end{tabular}

Notes:Materials,heat-treatment:M1-18XGT/HRC60;M1+mesurs ag.decarbonization;M2-42CrMo4/HB350;M3-42CrMo4/HB300 pos. 3. Toothed wrist with lower hardness (HB300); pos. 3.2 Treatment of gears "a" "“" g"-with measures against de-carbonization pos. 3.4 The deter med allowable general power at Kun=1,7 is $\mathrm{P}=505 \mathrm{~kW} \quad$ (against the requirement power of $500 / 400 \mathrm{~kW}$ ); 


\begin{tabular}{|c|c|c|}
\hline № & 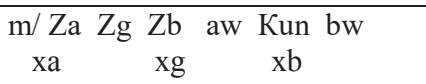 & $\begin{array}{l}\text { Allowable } \\
\text { Power, kW }\end{array}$ \\
\hline \multicolumn{3}{|c|}{$\begin{array}{llll}\text { First version : } & \mathrm{u}_{1}=4,0625 & \mathrm{u}_{2}=4,1654 & \mathrm{u}_{\mathrm{o}}=18,7501\end{array}$} \\
\hline $1-1$ & $\begin{array}{cccccc}6 / 32 & 33 & 98 & 197 & 1,5 & 160 \\
0 & & 0 & & 0 & \end{array}$ & $\mathbf{5 7 0} \mathbf{F} \quad 645 \mathrm{H}$ \\
\hline II-1 & $\begin{array}{cccccc}4 / 39 & 51 & 141 & 180 & 1,5 & \mathbf{9 0} \\
0 & & 0 & & 0 & \\
\end{array}$ & $620 \mathrm{~F} 850 \mathrm{H}$ \\
\hline \multicolumn{3}{|c|}{$\begin{array}{lll}\text { Second version : } \mathrm{u}_{1}=3,7501 & \mathrm{u}_{2}=5,0286 & \mathrm{u}_{\mathrm{o}}=18,8573\end{array}$} \\
\hline $1-1$ & 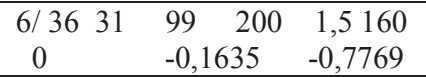 & $575 \mathrm{~F} \quad \mathbf{5 4 0 H}$ \\
\hline $1-2^{*}$ & $\begin{array}{lccc}6 / 3631 & 99 & 202 & 1,5160 \\
0,2367 & -0,0670 & -0,3875\end{array}$ & $\mathbf{5 9 5} \mathbf{F} \quad 600 \mathrm{H}$ \\
\hline II-1* & $\begin{array}{cccccc}4 / 35 & 53 & 141 & 176 & 1,5 & 90 ? \\
0 & & 0 & & 0 & \end{array}$ & $530 \mathrm{~F} \quad 665 \mathrm{H}$ \\
\hline II-2 & 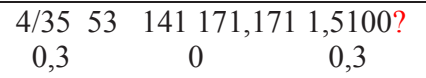 & $\mathbf{5 2 5} \mathbf{F} \quad 680 \mathrm{H}$ \\
\hline
\end{tabular}

A general strategy for reconstruction is the use of any opportunity to increase the admissible power of the gearing keeping the overall dimensions in the radial direction. And due to the presence of unevenness In this case, the load capacity sought is not strictly fixed.

And due to uneven loading of the satellites which is difficult to avoid, severe operating conditions and a need for faultless work, etc., the admissible power demanded is without a strict upper limit. Its higher level will also provide greater reliability for the multiplier.

An important point in this case is to clarify the theoretical and other constraints and the search for the best ways to comply with them or overcome them.
The author's software used here, includes different procedures for generating involute gearings within given theoretical and other limits. The output results present very exactly the areas of all possible solutions and parallel accompanying strength calculations. An example of a part of the information given to the constructor is shown in Fig.4. In the case under consideration, the planetary gearing of the multiplier is the most interesting at the second version of distribution of the general gear ratio $\mathrm{U}_{\mathrm{o}}$ (row I- $2 *$ ). The allowable power reached for the critical first step at a large reserve of unevenness, is a result of serious changes in the entire construction. The great increase of the allowable power of the first stage of the planetary transmission was achieved after reducing the huge width of the gears and reducing the deformations by installing bearings in the left and right sides of the planet carrier. The spline joint between the large pinion of the first planetary gearing and the planet carrier of the second stage is also changed. The increased strength of the new connection corresponds better to the high torque transmitted, and provides a technological distance for the spline shaft.

A further increase in overall load capacity has been sought and through variations in the distribution of the transmission between the two stages. In Table 4 with *), the highest load capacity variants obtained at $\mathrm{u} 1=3,75$ the weighted and $\mathrm{u} 2=4,06$ - of the high speed are noted. The new variants are better than the old ones.

\subsection{Increase of the oil bath and idea for a one- way hydro mechanical generator}

The changes of the housing provide a great space for oil. Because the high power of the multiplier, though his good efficiency, the amount of heat emitting is large and there is danger of increasing of oil temperature.

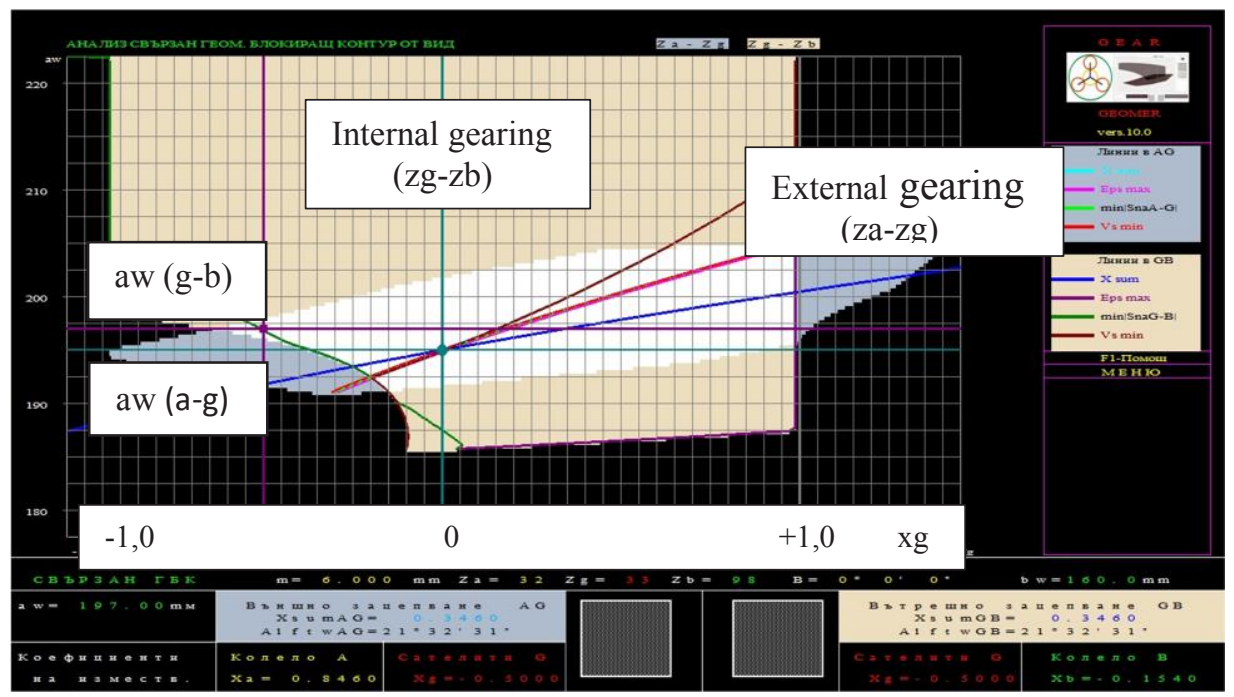

Fig.4 Connected/join Geometrical

Blocking Contours (C-GBC) of the

Slow moving stage of the multiplier

Data for the gearings Module $\mathrm{m}=6 \mathrm{~mm}$

Numbers of teeth:

$\mathrm{Za}=36 ; \mathrm{Zg}=31 ; \mathrm{Zb}=99$

Lines in the Graphics

-X $\Sigma$

-sum.add.m.coef.

•€max-

-tpans.cont.ratio

- min Sna-tooth thik. 
But in the given case the body of the transmission is constantly in contact with running sea water, taking out the heat energy, the temperature of the multiplier left low. $\mathrm{n}$ the course of operation, however, the lubricant deteriorates it's characteristics. For that reasons two lateral oil reservoirs have been added into the construction - in the outer central part of the hydro generator's tube, horizontally, in the direction of the axial line and situated higher than her. With an oil pump, a common circulation of the oil in the shell and the tanks is ensured. Under normal tidal conditions, heat energy from mechanical losses goes to the sea. In a version of the hydro generator created for unilaterally running water (for use at dams, for example), this heat could be utilized in a way which could increase the efficiency. An unidirectional version of the hydro generator can also be used to generate electricity from rivers, in the area around the midstream, where the hydro mechanical power generator could be mounted on floating structures remote from the bottom.

\section{Improving Parameters of multistage planetary gearboxes for hoists}

The second example is related with consulting service, supporting the industry at a new design project for hoists, in collaboration with TU - Gabrovo [7A]. The overall task was to develop a new preliminary model construction of a three-stage gearbox for electric hoists. From the point of view of the kinematics perspective for the development of parallel gearing families, the number of tooth of the internal gearings of the planetary stages is good to be $\mathrm{zb}=108$. From these positions, knowing the load requirements and the lifting speed, a proposal, supported by a preliminary design was made [ 7B]. There is also an orientation for selecting more technological blanks for the drum, respectively toothed high-strength thick-walled tubes. These requirements and features have shaped the version we have adopted as "starting," Table 5, Part A.

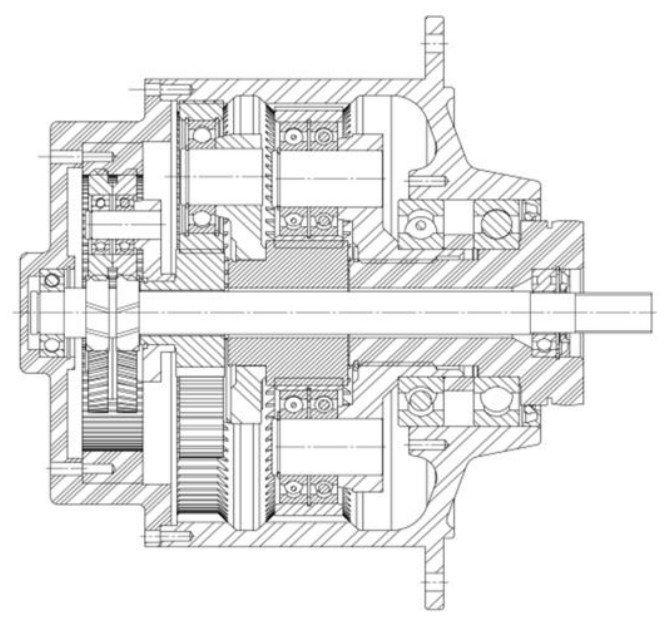

Fig.5 A version of three stages reducer for hoists

\begin{tabular}{|c|c|c|c|c|c|c|c|c|c|}
\hline \multirow{2}{*}{\multicolumn{10}{|c|}{$\begin{array}{l}\text { Table 5. Pameters of the "initial" version } \\
\text { of the gearbox for hoists }-50 \mathrm{kN}, \mathrm{V}=12 \mathrm{~m} / \mathrm{min}[7 \mathrm{~A}] \\
\text { Part A. Central internal gears with } \mathrm{Zb}=106 ; 108 \text { teeth } \\
\text { Load capacity of he three stages }\end{array}$}} \\
\hline & & & & & & & & & \\
\hline $\mathrm{C}$ & & $\begin{array}{ll}\mathrm{zg} \\
-\end{array}$ & $\begin{array}{c}\mathrm{Za} \\
-\end{array}$ & $\begin{array}{l}\mathrm{m}, \\
\mathrm{mm}\end{array}$ & $\begin{array}{l}\beta \\
(0)\end{array}$ & $\begin{array}{l}\text { bw, } \\
\mathrm{mm}\end{array}$ & \multicolumn{3}{|c|}{$\begin{array}{l}\text { PF } \\
\mathrm{kW}\end{array} \underset{\text { обща }}{\mathbf{P}}$} \\
\hline & 106 & 40 & 26 & 1,75 & 15 & 36 & 90a & 90ag & 90 \\
\hline & 108 & 39 & 30 & 2,50 & $\mathbf{0}$ & 40 & 35b & 26a & 6 \\
\hline & 108 & 36 & 30 & 2,50 & 0 & 40 & $12 \mathrm{~b}$ & $27 \mathbf{a}$ & \\
\hline \multicolumn{10}{|c|}{ Kun $=1 ;$ Materials -18 XГТ/HRC60; $42 \mathrm{CrMo} 4 / \mathrm{HB} 350$} \\
\hline \multicolumn{10}{|c|}{ Here all addendum } \\
\hline \multicolumn{10}{|c|}{ Part B. Central internal gears with $\mathrm{Zb}=96$ teeth } \\
\hline \multicolumn{10}{|c|}{$\begin{array}{l}\text { Load capacity of he three stages } \\
\begin{array}{|l|l|l|l}\beta & \text { bw, } & \text { PF } & \text { PH } \mathbf{P}\end{array}\end{array}$} \\
\hline $\mathrm{C}$ & $\begin{array}{r}\mathrm{zb} \\
-\end{array}$ & $\mathrm{zg}$ & $\begin{array}{c}\mathrm{Za} \\
-\end{array}$ & $\begin{array}{l}\mathrm{m} \\
\mathrm{mm}\end{array}$ & $\begin{array}{l}\beta \\
(\theta)\end{array}$ & & \multicolumn{3}{|c|}{$\mathrm{kW}$ обща } \\
\hline & 96 & 36 & 24 & 2,00 & 15 & 25 & 63ab & 53ag & 5 \\
\hline 2 & 96 & 34 & 27 & 3, & & 25 & 20 & 26 & \\
\hline & 96 & 32 & 32 & 3,00 & 0 & 40 & 11b & 19b & 11 \\
\hline \multicolumn{10}{|c|}{$\begin{array}{l}\text { Kun }=1,5 ; \text { Materials }-18 \mathrm{X} \Gamma \mathrm{T} / \mathrm{HRC} 60 ; \quad 42 \mathrm{CrMo} 4 / \mathrm{HB} 350 \\
\text { Gear ratios : u1 }=5,00 \mathrm{u} 2=4,55 \mathrm{u} 3=4,00 \quad \text { Ugen }=91,00 \\
\text { In the second stage } \mathrm{xa}=0,5293 \text {,the others coeff. are }, 06 .\end{array}$} \\
\hline
\end{tabular}

Follow the assignment, the required load capacity is:

$$
\mathrm{P}=\mathrm{F}(\mathrm{N}) * \mathrm{~V}(\mathrm{~m} / \mathrm{s}) /(75 * 1.36 * 10 \text {, equal about } 10 \mathrm{~kW} \text {. }
$$

From the first 3 rows of the Table 5 is seen, that the required load capacity is formally satisfied. But In fact, the three planet gears of the first two planetary gearings and the four planet gears of the third stages cannot transmit an equal load because of the existing unevenness. It is known that in such cases the coefficient of the unevenness is too big ( $\operatorname{Kun}>>1,0$ ), especially when the gearbox is without elastic or other special elements. [10], [11].

Normally the accuracy grades is worse than 7-7-7-B. Therefore, the admissible power of the "initial" version is insufficient and it needs a new solution. The Part B of Table 5 show a new version of the reducer in which the number of teeth on all gears have been changed.

The width of the first stage has been reduced just to bw $1=25 \mathrm{~mm}$, to assure (at angle $b=15^{\circ}$ ) constant value of the transverse contact ratio, decreasing the noise level. A new step in this direction could be the change of teeth number till 84-31-21, for example. The width of the second stage is also reduced, with a small reserve. Figure 5 shows a drawing of the new reducer. Here the body is a monolithic, but it can easily transformed into a variant for tubed billets. The first stage is in a separate lid and as it seen, hardly could cause any problem to be reduced more.

The smaller number of teeth in the second and third stages $(\mathrm{Zb}=96)$ is also prospective for production of joint "families" cylindrical reducers for the machine building. 
The second part of Table 5 also shows that the good results correspond to an achievable coefficient of unevenness Kun=1,5.

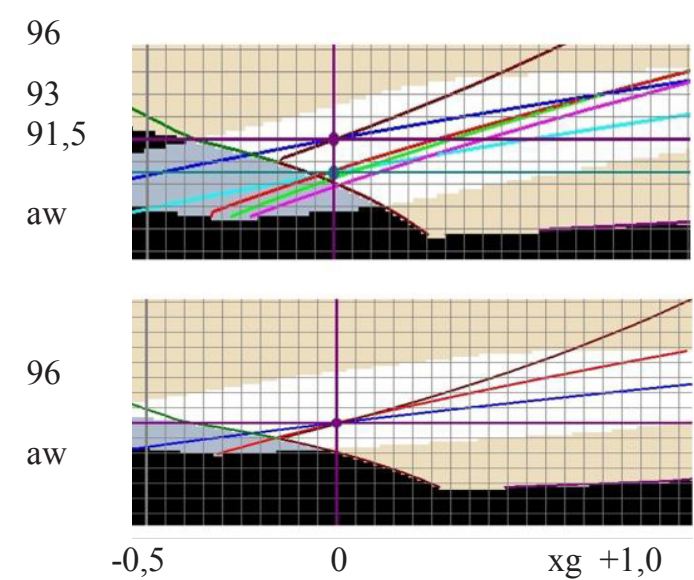

Fig.6 Double connected GBC in II and III stages

Below will be presented an unused spare possibility to increase the permissible load capacity of a connected planetary gears of multi-stage gears with an equal sizes of the central gears with internal teeth. The connection is multiple, real and conditional and is aimed to increase the admissible power by appropriate addendum modification coefficient of the gearing at to preserve complete identical of their geometric parameters.

The solution proposed in Fig. 6 with the GBC of the double connected of planetary gearing 2 and 3 is $\mathrm{xa} 2=0,5293$ at $\mathrm{xa} 3=\mathrm{xg} 2=\mathrm{xg} 3=0$ and zero modification coefficients of the two gear rings $z b 2=z b 3$. But it is possible a better result to be found in the free area of the two blocking contours.

An expanded version of Table 2 in the direction of the positive modification coefficients and the last row of Table 5 suggest that in the area of $\mathrm{xb} 2=0.3$ an round value of aw2 (not necessarily to integers) and a rounded values of aw1 as well as of corresponding coefficients xa1 and $\mathrm{xg} 1$ could be found.

\section{References}

1. P.Nenov. Parametrical optimization of cylindrical gear drives, 152 p. Pub.Technica, Sofia (2002)

2. P.Nenov,B.Kaloyanov,E.Angelova,V.Varbanov.Des. of gear drives by using of GBContours...126 p. Pub. UR, Ruse (2015)

3. MBFactory "Module“, Catalogs, Byala/Ruse (1974-2018)

4. P.Nenov, B.Kaloyanov, E.Angelova. Creating of connected Gear Blocking Contours...,Int.S.Ths.Pr.of Gearing-Proceeding, ITU-Izhevsk (2014)

\section{HYDROSYST, Documents, Ruse (2017-2018)}

A. Hydro mech. electro generator, A.Garvalov, EU-pro.

B. Plan.multiplier (,base“proj.),G.M.-TU/Plovdiv (2017)

C. Plan. multiplier (new ver.), P.N.,B.K.,Pl.D-UR (2018)
An even greater challenge is designing the gearing of the two connected last planetary stages (including associated external and internal gearing as shown in the figure). They are also considered as additional gears with the same module and the same number of gear teeth, with a totally identical tooth geometry, but with a displacement factor $\mathrm{xb} 2=\mathrm{xb} 3 \neq 0$

\section{Conclusion}

The modification of the two emblematic constructions ended with a significant improvement in their performance, thanks to the parallel-looking authoring program complex used for calculating and optimizing gears. It is a useful addition to the available software.

In order to avoid misunderstandings, it should be borne in mind that the author's package performs verification and design calculations. In both cases the strength characteristics are determined by the basic criteria - bending strength and contact strength.

However, for greater convenience, although there is constant information on stresses and torques, the results are controlled and evaluated at the permissible power of the gears in the position in which they are located, i.e., by reading the speed of rotation of the respective gears. Since in the majority of cases mechanical losses are relatively small, the weak links in the power chain are visible practically directly. This facilitates the global assessment of admissible power quickly directs the constructor's efforts to the weakest places.

The operation of the allowable power level corresponds to a load in which the calculated stresses in the gears drives are aligned with their permissible values. In a hypothetical version of complete equilibrium, all controlled capacities would be equal. That's why this design brings great clarity to the entire toothed mechanism and is particularly very suited to multi-stage gears. In them, the status assessment is the most complete and presents itself with potential opportunities, i.e., with the power that each of the meshes and their constituent elements can transmit.
6. V. Koudryavcev, J.Kedryachev. Planetary gear drives. Handboock, Machinbilding, Petersburg (1977)

7. TU-Gabrovo, NIS, Reducer for hoist,Doc. (2017-18)

A. „Initial project“ -I.Balachev, M.Penev, I.Stoianov, B. Plan.reducer for hoists-ver, UR -P.N.,B.K.,Pl.Danev

8. O. Alipiev, S. Antonov, T. Grozeva, Generalized model of undercutting of involute spur gears generated by rack-cutters. Mech. Mach. Theory 64, 39-52, (2013)

9. A.Mihailidis.Design optimization of high ratio Plan. Systems. Int.Conf. Power Transmissions -12 (2012)

10. V.Starjinskyi, E.Chalobaev and otr, Elements of mechanical drives, Belorusian science, Minsk (2011)

11. K.Arnaudov, D, Karaivanov, LDimitrov. Some pract problems of distribution ..., BAPT'12, Sinaia, (2012) 